\title{
Cardiovascular Disorders and Medicine
}

\section{Ouabain - A gift from paradise}

\section{Hauke Fürstenwerth* \\ Unterölbach 3A, D-51381 Leverkusen, Germany}

\section{Commentary}

Cardiovascular diseases are responsible for $>50 \%$ of total mortality. Among them, ischemic heart disease is the number one cause of mortality and morbidity in all industrialized nations. Heart failure, too, has emerged as an important cause of morbidity and mortality in developed countries. The five-year mortality from heart failure is over $50 \%$ and equals the one from cancer [1]. Medical therapies for heart disease are based on a diverse range of drugs that only improve clinical symptoms and slow the progression of contractile dysfunction. Novel therapeutic strategies for protecting the heart are urgently needed. Of special importance are efforts that mimic endogenous mechanisms to protect the heart.

During the past decades, intensive research on "ischemic conditioning" - applying brief episodes of nonlethal ischemia and reperfusion to confer protection against a sustained episode of lethal ischemia and reperfusion injury - has shown that cardioprotection is indeed possible by conditioning of the heart with nonlethal ischemic episodes [2]. Ischemic preconditioning today is the most effective, reproducible form of protection against myocardial cell death yet described. The molecular mechanisms underlying cardiac protection by ischemic conditioning have been identified. A range of signal transduction pathways is activated that protect the heart [3]. A variety of pharmacological agents have been identified that are capable of reproducing the cardioprotective effects of ischemic conditioning. Despite a wealth of preclinical, experimental animal data demonstrating clear cardioprotective benefits with these treatment strategies, their translation into clinical therapy has been hugely disappointing [4]. The ultimate goal still is to find drugs that mimic the effects of ischemic conditioning and allow pharmacological preconditioning that protects the heart and other tissues from the deleterious effects of oxygen deficiency.

The Strophanthus glycoside ouabain - in the German literature referred to as g-Strophanthin - has been shown to mimic the effects of ischemic conditioning [5]. Unlike the short lasting effects of hypoxia and preconditioning with brief episodes of ischemia the cardioprotection induced by ouabain is maintained for hours. Cardioprotection induced by ouabain is due to the activation of pathways that are also activated in ischemic preconditioning. Just like ischemic preconditioning, ouabain activates the RISK pathway. Activation of NF-kB and other transcription factors contribute to the long lasting effects of ouabain. These observations clearly make a clinical reevaluation of ouabain necessary. In decades of clinical experience, the cardioprotective effects of ouabain have been demonstrated. The therapeutic profile and the disease profiles for which the use of ouabain is appropriate are documented in many reports on clinical experiences and have been summarized in numerous reviews, preferably in the German literature [6]. As early as the first half of the 20th century distinguished scientists such as Albert Fraenkel, University of Heidelberg, and Ernst
Edens, University of Dusseldorf, have published monographs $[7,8]$ that document in detail the clinical effects of Strophanthus glycosides.

The extensive clinical experiences with ouabain are complemented by experimental in-vitro and in-vivo studies that indicate cardio protective effects. Ouabain prevents hypertrophy of the heart and the adrenal cortex in rats exposed to hypoxia induced by extreme exercise. In rat and rabbit hearts short exposure to a low concentration of ouabain protects the heart against ischemia/reperfusion injury. Current reports confirm cardio protection induced by ouabain [9]. It is suggested that ouabain can be beneficial to various stages of heart failure [10]. In addition, experimental results indicate promising effects of ouabain in cancer and protection of kidney development from adverse effects of malnutrition.

In stark contrast to decades of positive clinical experiences with ouabain in humans, in current research reports several disease states are reported to be associated with elevated levels of a compound that is claimed to be "endogenous ouabain". It has been asserted that "ouabain is a key factor in the pathogenesis of hypertension and heart failure" [11]. The concept of "endogenous ouabain" (EO) originated in the late 1970s when it was postulated that an endogenous inhibitor of vascular $\mathrm{Na} / \mathrm{K}$ ATPase might be a natriuretic hormone $(\mathrm{NH})$ causing hypertension [12]. Because of the suggestion that $\mathrm{NH}$ might be an inhibitor of $\mathrm{Na} / \mathrm{K}$ ATPase, it was subsequently referred to as "ouabainlike" or "digitalis-like." By using radioimmunoassays (RIA) based on digoxin or ouabain antibodies numerous compounds have been identified in mammalian plasma, including steroids, lipids, peptides, and a variety of other novel compounds [13]. Antibody based RIA are often subject to cross reactivity with compounds other than those to which the antibody was raised. A current example is ionotropin. This substance has been isolated from mammalian tissue. It cross reacts with digoxin-specific antibodies, but has a proposed chemical structure that is not related to digoxin [14].

It is important to note that the EO concept, in contrast to clinical experience, suggests that digoxin and ouabain as inhibitors of the sodium pump increase blood pressure. However, in more than two centuries of clinical use with therapeutic concentrations of digoxin and ouabain no hypertensinogenic effects have been observed. In clinical experience a reduction of high blood pressure in patients is observed especially on treatment with ouabain [15]. Already Thomas Fraser, who in cooperation with Burroughs, Wellcome \& Co in 1886 had introduced a Strophanthus extract for the treatment of heart diseases, had pointed out that "strophanthin increases the action of the heart without raising blood pressure."

*Correspondence to: Hauke Fürstenwerth, Unterölbach 3A, D-51381 Leverkusen, Germany, Tel: +49 2171733740; E-mail: hauke@fuerstenwerth.com

Received: June 14, 2018; Accepted: June 19, 2018; Published: June 22, 2018 
In 1991, Hamlyn et al. reported purification of a compound indistinguishable from ouabain by mass spectroscopy from 3001 of human plasma [16]. Subsequent work seemed to confirm this observation and indicated that mammalian ouabain is present in multiple body fluids and tissues. In his review on the history of endogenous digitalis-like factors Vardaman Buckalew points out that the issue of whether mammalian tissues contain authentic ouabain has remained highly controversial [12]. Conflicting results, hubris and personal vanity characterize the research on endogenous ouabain. The mutually exclusive effects of ouabain and the inhibitor of the $\mathrm{Na} / \mathrm{K}$ ATPase observed in mammalian tissues do not support the hypothesis that this inhibitor is identical with ouabain, but favor the interpretation that the $\mathrm{NH}$ is something different, which also reacts to ouabain antibodies.

Vogeser et al established a stable-isotope dilution API-MS/MS method for the quantification of ouabain in human plasma [17]. They were able to develop a method of extremely high sensitivity detecting spiked ouabain in human plasma. The method was fully validated according to FDA guidelines and published in the official journal of the International Federation of Clinical Chemistry after peer review. Using this method, they could not detect ouabain within the calibration range of the method (1.7-172 pmol/l) in any of the analyzed unspiked human plasma samples that contained EO levels of 206-665 pmol/l as determined by RIA in an independent laboratory. These results confirm that there is no endogenous ouabain in human plasma. In a series of publications Mordecai P. Blaustein, who strongly advocates the EO concept, vigorously denies the results of Vogeser's laboratory $[11,18,19]$. With dubious claims and even unfounded accusations ("edited their raw data" "scientific misconduct") he tries to discredit Vogeser's method. In addition Blaustein does not even mention the fact that ouabain has been used successfully in medical therapy of heart failure [20]. He ignores ideas and data that don't fit his preconceptions and neglects conflicting results that don't support his hypotheses. Blaustein's narrative about the construction of an "endogenous ouabain- $\mathrm{Na}+$ pump endocrine system" lacks a necessary critical perspective. It is guided by wishful thinking and not by facts.

Science is a set of methods aimed at building a testable body of knowledge open to rejection or confirmation. Such an understanding of science should also form the basis in research on ouabain. Hubris and personal vanity will hinder finding the truth, but they can not stop it. In the end, truth does prevail. For the locals in Africa, Strophanthus was poison and remedy in one. In the mythology of the tribe of the Wilé in Upper Volta, this plant was sent from paradise to the earth to heal or punish people according to their merit [21]. A clinical reassessment of ouabain offers an unique opportunity to transform this gift from paradise into much needed new treatment options for cardiovascular diseases.

\section{References}

1. Stewart S (2003) Prognosis of patients with heart failure compared with common types of cancer. Heart Fail Monit 3: 87-94. [Crossref]

2. Hausenloy DJ, Yellon DM (2011) The therapeutic potential of ischemic conditioning: an update. Nat Rev Cardiol 8: 619-629. [Crossref]

3. Vinten-Johansen J, Shi W (2011) Preconditioning and postconditioning: current knowledge, knowledge gaps, barriers to adoption, and future directions. J Cardiovasc Pharmacol Ther 16: 260-266. [Crossref]

4. Candilio L, Hausenloy DJ, Yellon DM (2011) Remote ischemic conditioning: a clinical trial's update. J Cardiovasc Pharmacol Ther 16: 304-312. [Crossref]

5. Fuerstenwerth H (2014) Ouabain--the key to cardioprotection? Am J Ther 21: 395-402. [Crossref]

6. Fürstenwerth H (2010) Ouabain - the insulin of the heart. Int J Clin Pract 64: 15911594. [Crossref]

7. Fraenkel A (1933) Strophanthin Therapie, Verlag Julius von Springer, Berlin

8. Edens E (1948) Die Digitalisbehandlung [Digitalis treatment], Third edition, BerlinMünchen, Verlag Urban\&Schwarzenberg.

9. Wu J, Li D, Du L, Baldawi M, Gable ME, Askari A, Liu L (2015) Ouabain prevents pathological cardiac hypertrophy and heart failure through activation of phosphoinositide 3-kinase a in mouse. Cell Biosci 5:64. [Crossref]

10. Liu L, Wu J, Kennedy DJ (2016) Regulation of Cardiac Remodeling by Cardiac $\mathrm{Na}(+)$ $\mathrm{K}(+)$-ATPase Isoforms. Front Physiol 7: 382. [Crossref]

11. Blaustein MP (2018) The pump, the exchanger, and the holy spirit: origins and 40-year evolution of ideas about the ouabain-Na+ pump endocrine system. Am J Physiol Cell Physiol 314: C3-3C26. [Crossref]

12. Buckalew VM (2015) Endogenous digitalis-like factors: an overview of the history Front Endocrinol (Lausanne) 6: 49. [Crossref]

13. Wechter WJ, Benaksas EJ (1990) Natriuretic hormones. Prog Drug Res 34: 231-260. [Crossref]

14. Chasalow F, Pierce-Cohen L (2018) Ionotropin is the mammalian digoxin-like materia (DLM). It is a phosphocholine ester of a steroid with 23 carbon atoms. Steroids 136: 63-75. [Crossref]

15. Fürstenwerth H (2015) Ouabain and Endogenous Ouabain -Dr. Jekyll and Mr. Hyde of Cardiac Glycosides? British Journal of Medicine \& Medical Research 8: 477-484.

16. Hamlyn JM, Blaustein MP, Bova S, DuCharme DW, Harris DW, et al. (1991) Identification and characterization of a ouabain-like compound from human plasma. Proc Natl Acad Sci U S A 88: 6259-6263. [Crossref]

17. Baecher S, Kroiss M, Fassnacht M, Vogeser M (2014) No endogenous ouabain is detectable in human plasma by ultra-sensitive UPLC-MS/MS. Clin Chim Acta 431 87-92. [Crossref]

18. Blaustein MP (2015) Letter to the Editor concerning Baecher et al. (Clin Chim Acta 2014;431:87-92). Clin Chim Acta 448: 248-249. [Crossref]

19. Blaustein MP (2018) Reply to "Letter to the editor: Comments on Blaustein (2018): 'The pump, the exchanger, and the holy spirit: origins and 40-year evolution of ideas about the ouabain-Na+ pump endocrine system'”. Am J Physiol Cell Physiol 314: C641-641C642. [Crossref]

20. Fürstenwerth H (2014) Letter to the editor: "Why isn't clinical experience with ouabain more widely accepted?". Am J Physiol Heart Circ Physiol 307: H1262-1263. [Crossref]

21. Leuenberger H (1972) Gesund durch Gift, Deutsche Verlagsanstalt Stuttgart

Copyright: (C2018 Fürstenwerth H. This is an open-access article distributed under the terms of the Creative Commons Attribution License, which permits unrestricted use, distribution, and reproduction in any medium, provided the original author and source are credited. 